\title{
Editorial
}

\section{Funding long-term liabilities: A global perspective - CFA Institute Annual Conference}

\author{
Alan Brown \\ is Head of Investment, Schroder Investment Management Limited. \\ 31 Gresham Street, London EC2V 7QA, UK \\ Tel: +44 0207658 6575; Fax: +44 0207658 6400; E-mail: Alan.Brown@schroders.com
}

\section{Introduction}

The provision of adequate pensions to the retired population is an important aspect of social policy in all developed countries. Almost everywhere, pensioners rely on some combination of state provided (1st Pillar) and employee sponsored (2nd Pillar) systems. Most of us here today are concerned in one way or another with funded 2nd Pillar savings systems.

With bond yields declining to near generational lows, and with liabilities increasingly being discounted at market rates, funding ratios of pension plans have come under extreme pressure. In the space of three years, funding ratios in the US fell from an average of about 115 per cent to around 80 per cent (source: Watson Wyatt). In the face of such intense pressure, industry best practice has come under scrutiny. This Editorial starts by questioning some basic assumptions about funded pension systems in general, and then challenges today's standards of best practice. Finally, it attempts to address the following more focused topics:

- Fixed income: There is a move away from benchmark oriented strategies towards either
— liability-based portfolios, or

- absolute return strategies.

- Equities: In the search for higher and more consistent alpha, investors are considering:

— '130/30' portfolios

- benchmark unaware strategies, and - alpha transport strategies.

- Alternatives: The industry is evolving from single or fund-of-funds strategies towards multi-strategy solutions.

- It concludes with a case study drawn from the Schroder Benefit Retirement System.

The common theme among these focused topics is improving risk/return dynamics and finding ways to improve efficiency and cost effectiveness. In a world of low nominal returns, managing risk and improving net returns is vital in order to deliver on the pension promise that society demands.

\section{Funded versus pay-as-you-go pension systems}

The investment management industry regards it as almost axiomatic that funded pension systems are superior to unfunded, pay-as-you-go systems. Without making some important 
assumptions, however, it is not in fact obvious that one system is superior to another, at least at the macro level.

Consider a closed economy, an assumption that can be relaxed in a moment. The GDP of the country is produced by the workers and consumed by the workers and non-workers, pensioners, unemployed and children. To the extent that pensioners and children get to eat or consume anything, there is a transfer of income from workers to non-workers.

What one must consider, then, is why a transfer mechanism based on savings and capital markets (funded) should be better than one based on taxation and borrowing (pay-as-you-go). One argument might be that a funded system lowers the cost of capital, thereby helping to grow a bigger pie. Another similar argument would be that the private sector is more efficient at allocating capital. These, though, are quite subtle arguments.

Now, if the closed economy constraint is relaxed, does that change the argument? Not if all we do is expand our horizons to countries with similar dependence issues. All that happens is the problem is writ on a larger scale.

Interestingly, there is in the limit one funded pension system which becomes exactly the same as pay-as-you-go with no possible macro advantage. While this may be regarded as a reductio ad absurdum, in a world where defined benefit (DB) plans are getting more mature and asset allocations are moving more towards fixed income, the point becomes non-trivial. Consider a pension fund invested entirely in government bonds. W.H. Smith in the UK is almost one such fund as, apart from a 6 per cent call position on equities, it is all in bonds or swaps. Government bonds are re-paid out of taxation or further borrowings. A pension fund invested purely in government bonds is therefore no more or less than an extension of the pay-as-you-go system, a rose by any other name. And, in fact, one such system exists already, and it is large. We refer, of course, to the social security system in the US, which holds large quantities of US government bonds on its books.

It must, then, be recognised that, for funded pension systems to provide a macro benefit for the economy as a whole, investments must in some sense be 'wealth creating'. This then leads to the next general point, and that is the whole question of best practice today.

\section{Best practice}

Thinking about best practice as it stands today, the following five-stage process is used as a short-hand description.

- Conduct an asset/liability study to determine a strategic benchmark.

- Construct an implementation plan around that benchmark - typically combining a mix of specialist managers in both active and passive strategies.

- Conduct a manager search to fulfil the implementation plan.

- Fund and monitor managers.

- Repeat every three to five years.

If that sounds like a reasonable process, it is really only because it has become the accepted norm, and we have stopped considering all the assumptions and implications inherent in it.

First, after the initial asset/liability study, the benchmark becomes the effective numeraire against which almost everything is judged. As a result, the great majority of our governance budget is being employed to manage the risks of our portfolio to the benchmark. These risks are generally small and sometimes 
actually trivially small. Risks from the benchmark to the liabilities, which are large, are only 'managed' intermittently when the asset/liability study is repeated every three to five years. In effect, we are spending 80 per cent of our time on 20 per cent of the problem, rather than the other way round.

The effect of this was to leave the industry paralysed as asset prices first rose to giddy heights at the end of the Technology, Media and Telecommunications (TMT) bubble and then subsequently collapsed. On the way up, the industry somewhat complacently congratulated itself as surpluses mushroomed and contribution holidays were extended. On the way down, there was much hand wringing but little action. In effect, the industry behaved like a rabbit caught in the headlights, unable to turn to the left or to the right.

There are other consequences which follow on from making the benchmark the reference point against which risk is measured. So, for example, if one chooses to overweight, say, long-dated index linked securities, risk as measured against the benchmark increases, whereas typically risk relative to nearly all funds liabilities actually falls. What appears as a risky move in one context is actually risk reducing in liability space.

Asset/liability modelling also has some wholly unrealistic assumptions buried in it that most of us have forgotten, if we ever really even thought about them. Assumption number 1 is that an investor's risk appetite does not change with wealth. Assumption 2 is that an investor's risk appetite does not change with shifting opportunities from taking risk (risk premia). Both of these assumptions are transparently wrong. Not only are almost all investors sensitive to their wealth (even if they should not be), but very real world events happen to pension funds as wealth (funding ratios) declines. And on risk premia, clearly investors should be happier to take on risk if risk premia are high, and less happy if they are low.

Conventional asset/liability modelling is essentially a myopic process, by which we mean that it does not consider the path taken to get from A to B, merely the end points. Essentially, it is a single period optimisation with one set of expected returns and one risk-aversion parameter. The results may be stress tested with Monte Carlo analysis, but the assumptions do not change.

This leaves one wondering why we are making these assumptions in the first place. To do anything better requires one to move from a static, myopic model, to a dynamic, intertemporal approach. The theory on continuous time finance has been around for years much of it developed by Robert C. Merton (see Selected Bibliography). He has published extensively on the topic from the late 1960 s on. Merton was finally awarded a Nobel prize for his work on derivative pricing in 1997.

The problem is that the mathematics involved is exceedingly complicated and, until recently, largely intractable for real-world problems. But with the computing power available today, these equations can now be solved using numerical techniques. For the purposes of this paper, it is not necessary to get into the detail, but we do want to explore in general terms the richness of moving to a more dynamic modelling environment and how it informs the whole investment management process.

\section{Dynamic policies rather than static benchmarks}

As soon as we start to think in a more dynamic sense, we find ourselves having to think of the investment management problem in a much more holistic way. 
So, for example, one of the first observations we can make is that generally risk premia and wealth move in opposite directions. Pension funding ratios tend to improve when equities outperform bonds but, when equities materially outperform bonds, risk premia tend to decline.

Should, then, risk appetite be governed more by changes in funding ratio or changes in risk premia? The answer to this question will depend on the risk preferences of the pension fund Trustees, and this in turn is likely to be conditioned on the strength of the implied covenant with the fund sponsor and the regulatory environment in which the fund operates. If the implied covenant with the fund sponsor is strong, it is quite possible that Trustees will not feel obliged to reduce risk budgets as funding ratios decline, preferring instead to consider increasing future opportunities through rising ex ante risk premia. But, if the implied covenant is weak or the regulatory environment harsh, Trustees may well feel that they have no choice in the face of declining funding ratios other than to reduce risk budgets and so limit potential further declines in wealth.

As an aside, there is an essential difference in time dimension between risk premia and wealth measures. Funding ratios can be measured as frequently as we choose and are a 'point-in-time' measure, like a balance sheet. Risk premia are return estimates which will only be realised (if at all) over multi-year horizons.

For all these reasons, wealth measures, funding ratios for pension plans and solvency margins for insurance companies are likely to be the main driver of risk budgets for most investors.

As we have started to think about this, note that we have moved from a discussion about benchmarks to a discussion about risk budgets. When wealth measures are the main driver, our numeraire has become the fund's liabilities, and it is against the fund's liabilities that we are measuring our risk budget. Now, if we overweight inflation-linked securities in our portfolio, our portfolio risk declines. For the first time, the investment problem that we are attempting to manage is aligned with the real-world goals of the Trustees. In effect, we have moved into a framework of surplus management where we measure the excess of assets over liabilities and make that determine our risk policy.

There is another implication of this, which again connects us firmly with the real world. Today, benchmark risk in portfolio optimisations is treated symmetrically. That is to say, upside risk is given equal value to downside risk, even though we all acknowledge that the two are quite different. We have an unlimited appetite for upside risk; our aversion is purely to downside. By moving into a framework of surplus management, we have explicitly recognised this. Typically, for most funds, as wealth increases so does risk appetite and vice versa. What this implies is that we put a value on skewness. We want to truncate the left-hand side (downside) half of our return distribution.

So what we are arguing for is that we should move away from strategic benchmarks and replace them with strategic policies where the strategic policy states in advance how a fund's risk budget should be conditioned on its funding ratio and risk premia. Adopting such an approach would mean that the fund's real-world objectives are actually encapsulated in their strategic investment policy. Return goals now become subject to whatever are the real-world considerations of the Trustees, such as surplus or funding volatility, or minimum 
funding ratios. The liabilities of the fund become the numeraire and, as the strategic policy reflects real-world objectives, the interests of the fund and their managers are for the first time truly aligned.

There are a couple of other implications which pretty much follow-on from a move towards a more dynamic asset allocation policy.

First, it will encourage the separation of alpha, skill-based-return generation, from the capturing of market beta (a topic we return to later). No longer will it make apparent sense to employ the fund's alpha risk budget in the same asset classes as the strategic benchmark, as the benchmark itself will be subject to change. Instead, skill-based risks will be taken in areas where the potential for skill-based rewards is high.

Secondly, with liabilities now firmly at the centre as the numeraire of the fund, this highlights the large and unrewarded tracking error between conventional fixed-income market benchmarks and the liabilities of a typical pension fund. As a result, we see a move towards more structured, swap-based fixed-income portfolios which link much more closely to a fund's actual liabilities, thereby releasing today's wasted risk budget for hopefully more profitable purposes. Alternatively, more return-conscious investors will move towards more absolute return strategies. We now consider this further.

\section{Fixed Income}

As investors have focused more on risk relative to actual liabilities rather than to strategic market-related benchmarks, this has highlighted significant weaknesses in current fixed-income practices.

Fixed-income portfolios have traditionally been regarded as the low-risk, more conservative part of portfolios, which are more closely linked to a fund's liabilities. The reality is, however, that most market-related benchmarks have a significant tracking error to most funds' actual liabilities. Worse, there is no expectation of any increased return coming from that tracking error. Indeed, in positively sloped yield curves, investors are giving up a term premium by being short duration.

On closer examination, it becomes less and less clear as to why the industry has focused on market-related benchmarks. There is no financial theory for government bonds, the equivalent of the Capital Asset Pricing Model (CAPM) for equities, to suggest that investors should buy bonds in their market capitalisation proportions. Moreover, if in the past market-related benchmarks at least represented the broad opportunity set, that is no longer the case now that the swap and derivatives markets rival, and in some cases exceed, the size of the cash markets.

Investors are also very aware of the possibility that yields (nominal, real and credit spreads) may be close to generational lows (Figures 1-3).

\section{Consequence}

The impact of both a reappraisal of bond investing from a liability perspective, and the current low level of yields, has taken fixed-income investors to a 'fork in the road'.

Some investors, concentrating on risk, have moved in the direction of building fixed-income portfolios which more closely match their liabilities through so-called LDI portfolios.

Other, more return-conscious, investors concerned about the low level of yields have moved in the direction of absolute return strategies. While mandates vary significantly, they are generally defined in the following way: 


\section{US Ten Year Nominal Yield}

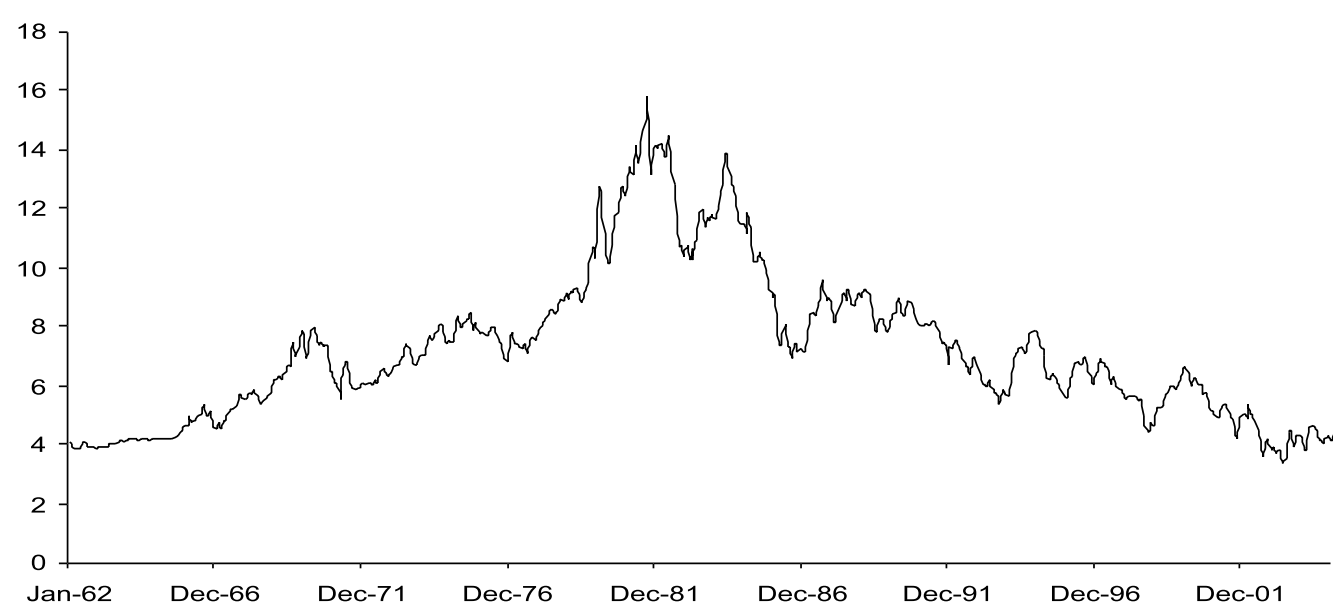

Figure 1 US ten-year nominal yield

US Ten Year Real Yield (deflated by headline Inflation)

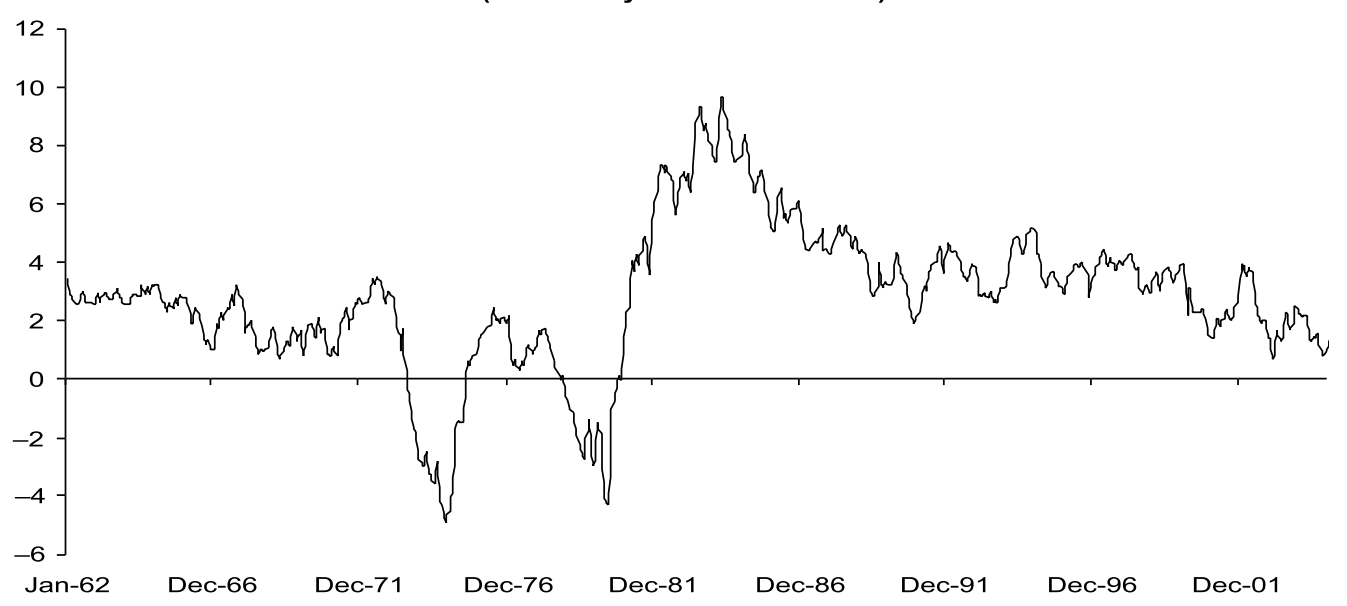

Figure 2 US ten-year real yield (deflated by headline inflation)

- Benchmark: LIBOR+x per cent

- Duration: short and long positions allowed within limits

- Credit: short and long positions allowed within limits

- Leverage: permitted within limits.

We shall return to the question of leverage again later, and we shall return to the question of benchmark unaware strategies again in the context of equities.

\section{Unintended consequences}

In the UK, yields taken from the government bond market yield curve are used to value pension liabilities. The size of the pension market, however, dwarfs the size of the government bond market. As a result, as money has moved into long-dated government bonds and swaps in an attempt to reduce accounting exposures, there has been a substantial imbalance of supply and demand which 


\section{US IG Credit Spreads}

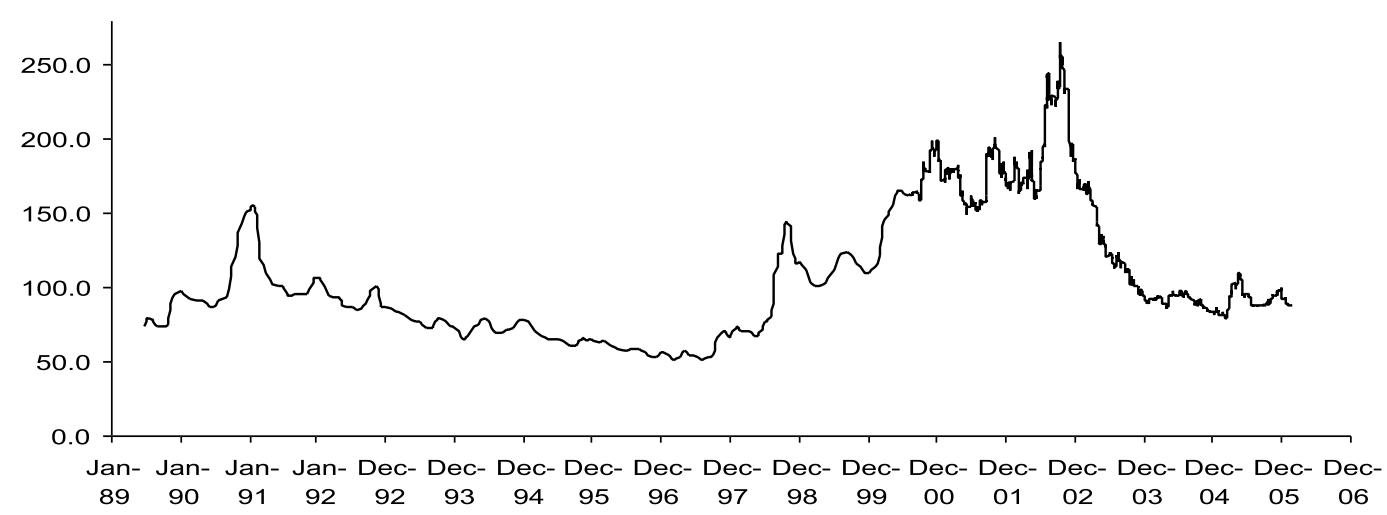

US Corporate Index

Figure 3 US IG credit spreads. Source: Bloomberg

has distorted the shape of the yield curve. Long-dated real yields have fallen to below half of 1 per cent. Of course, declining real yields have the effect of raising liabilities, which has the effect of increasing demand for long-dated assets, which has the effect of further depressing yields.

At such low yields, many investors take the view that it simply does not make economic sense to lock up assets at $\frac{1}{2}$ per cent real yields and are therefore forced to continue to run the accounting exposures.

\section{Equities}

Most institutional investors quite rationally expect lower returns from financial markets than was commonplace for most of the 1980s and 1990s. In a world of single-digit return expectations, the impact of costs becomes ever more important.

Moreover, where explicit funding ratios are stretched, investors are faced with only three practical choices:

- increase contributions
- reduce benefits

- run more aggressive strategies in the hope of bridging the return gap.

Unsurprisingly, many investors opt for the latter choice, proof if it were ever needed, that Samuel Johnson's 'Triumph of Hope Over Experience' is alive and well!

In the pursuit of higher alpha, managers are being encouraged to produce more concentrated, 'best ideas' funds. While this may help some investors, it is most unlikely to solve the problems of the industry as a whole. We cannot avoid two issues. First, alpha generation is necessarily a negative sum game. The return earned by all investors equals the return of the market less intermediary charges of commissions and bid-offer spreads. Secondly, as portfolios become more concentrated, there is a real danger that risk and not return will be increased. Investors are paid to take risks, but only those risks that cannot be diversified away.

A concentrated portfolio solution to the pursuit of alpha relies on the asset owner's being able to identify ex ante 
superior managers. Some will clearly succeed in this, others, probably the majority, will not.

We believe that there are three other alternatives that are worthy of consideration in bridging the return gap. Each of these has, we believe, good theoretical support and, increasingly, a body of supportive practical evidence.

\section{'130/30' portfolios}

Richard Grinold (1989) published a seminal paper entitled 'The Fundamental Law of Active Management'. Widely accepted by practitioners and academics alike, the essence of the paper was that an investor's return/risk ratio was proportional to their skill and the breadth (actually the square root of breadth where breadth is the number of independent 'bets' in a portfolio) of their strategy.

$$
I R \infty I C \times \sqrt{N}
$$

where $I R$ is the return-to-risk ratio, IC is the information coefficient (correlation of forecasts to outcomes), and $N$ is breadth.

So, a strategy such as stock selection would have much greater breadth than say, a strategy of market timing. For both strategies to have the same information ratio, then, a market timing manager would need to have much greater skill. This is why most managers prefer to concentrate their efforts on stock selection.

In 2002, Grinold's work was extended in a most insightful way in a paper entitled 'Portfolio Constraints and the Fundamental Law of Active

Management'. Clarke et al. (2002) introduced the concept of the transfer coefficient (TC) and extended Grinold's equation so that

$$
I R=T C \times I C \times \sqrt{ } N
$$

The transfer coefficient is simply the correlation between the manager's actual active portfolio positions and his/her forecasts. The importance of this cannot be overstated. In a normal long-only mandate, the TC is impacted by transaction costs, prudent max and min limits, and the benchmark. Even in a broadly diversified benchmark such as the S\&P500, the correlation between actual positions and forecasts is often 0.3 or lower. Essentially, 70 per cent of a manager's good ideas (assuming he has some!) do not get into the final portfolio. The reason is clear. If you have a negative view on Exxon or GE, you probably have plenty of room to underweight them. But many stocks have a weight in the index of 10 basis points or less. If a manager has a negative view on those stocks, he/she cannot reflect that in his/her portfolio. Allowing a manager to go short by some 30 per cent or so provides sufficient freedom for most managers to be able to reflect their negative views. This should allow the correlation between the manager's positions and forecasts to nearly double to between 0.5 and 0.6 .

Although one can view such a strategy as leveraged alpha, the main purpose is to improve the information ratio. In essence, a manager with skill should be able to increase their information ratio by say 60 per cent, providing the opportunity to increase returns by some 60 per cent while maintaining risk levels.

While such portfolios offer perhaps the best opportunity to improve risk-adjusted returns, there are two key practical issues that need to be dealt with.

- Trustees need to be comfortable with the idea of shorting stocks.

- Managers need experience in shorting stocks and managing prime broker relationships. 
There are technical reasons as to why this kind of strategy is more easily delivered by quantitative rather than traditional strategies. This is largely because quantitative strategies tend already to be broadly diversified, and secondly, quantitative strategies routinely rank all stocks in the benchmark universe.

Institutional support for these approaches recently received a significant boost with the announcement by CalPERS and its consultant, Wiltshire, that they were going to employ the strategy (see Appendix).

\section{Benchmark unaware strategies}

The CAPM (Sharpe, 1964) has stood the test of time remarkably well. CAPM is a partial equilibrium model which simply states that, in an efficient (or reasonably efficient) market, the portfolio with the best risk-adjusted returns is the market portfolio. And indeed, if one looks at returns in a historical context, the evidence is quite compelling. The MSCI Cap Weighted index normally ranks over most time periods in the first or second quartile among individual country returns. Of course with 20:20 hindsight, there are always some markets which have delivered higher returns but, as an ex ante strategy, it has been hard to beat.

Increasingly, however, it is recognised that the assumptions embodied in CAPM are very much idealisations and do not accurately represent the real world. Few practitioners or academics today believe that markets are efficient in the strict sense, and an increasing body of opinion is questioning capitalisation weighted benchmarks.

Robert Arnott (Editor of the Financial Analysts Journal among other things) recently published a paper (Arnott et al., 2004) challenging market capitalisation benchmarks, and proposing instead indices weighted on 'real-world measures' such as sales, book assets, number of employees etc. In this, he produced evidence that, over an extended period of time, such an index had outperformed conventional market capitalisation-based indices, in both absolute and risk-adjusted terms.

Critics argue that such an index has an inherently small cap and value bias and that that accounts for most of the return differences. But what if small size and value characteristics are actually positively associated with higher returns, as argued by Fama and French (1992)?

It is in fact possible to argue, even as a believer in efficient markets, that value indices may have attractive return characteristics. If one assumes that the market is constantly trying to determine the right price for assets and is as likely to overestimate as it is to underestimate the value of stocks, then, by definition, the growth half of an index will have more-overvalued companies in it than under-valued, and vice versa for the value half of the index.

The recent experience of the bubble in TMT stocks and the market generally illustrates the issue. Any manager with a value or small cap bias underperformed materially in 1998 and 1999, but then recovered even more dramatically in the 2000-02 bear market. Importantly, a value strategy not tied to the benchmark may actually have avoided negative returns in the down years for the markets as a whole. Giving up returns in very good years to gain protection in poor years is a highly valuable attribute, particularly in the context of strategies which are increasingly trying to manage surplus volatility and funding ratios directly.

It stands to reason that there will be times when whole sectors or whole countries will become relatively overpriced. A strategy which is tied to a benchmark has little choice but to continue to hold such overpriced assets. 
A manager who is free to roam has the opportunity to rotate out of overpriced sectors or countries as markets overreact in both directions.

There are practical considerations in employing unconstrained strategies. A move towards 'benchmark unaware' strategies requires a different approach to assessing relative returns. Inevitably, there will be years when market cap weighted strategies will outperform. And, as a direct corollary of being 'benchmark unaware' an unconstrained mandate will carry sizeable and quite probably variable factor bets against the popular benchmarks. We believe that a measure of return which is more relevant for such strategies is the realised Sharpe ratio over time (return of portofolio minus risk-free return divided by standard deviation of portfolio returns). In the long run, such strategies should deliver superior Sharpe ratios to market cap benchmarks.

\section{Alpha transport (portable alpha)}

Given the development of the derivatives and swaps markets, it is increasingly possible to separate alpha (skilled based) strategies from beta (market) capture. A powerful argument can be made that, where managers today attempt to provide alpha at the same time as capturing market risk premia, neither activity is optimised. Beta capture is inefficient and expensive, and alpha generation is inhibited both by the restrictions imposed by a long-only benchmark (as discussed above) and a fund's strategic benchmark. So, for example, US funds understandably have large allocations to large-cap US equities, arguably the most efficient equity market in the world. Why would a fund want to employ much of its active risk budget in an efficient market such as large cap US equities, when potentially that risk budget could be employed in less-efficient markets where the chances of success are much greater?

Alpha transport strategies hold out the potential of employing a fund's active risk budget in inefficient markets and then swapping the resulting market exposures back to the fund's strategic (beta) benchmark using the derivatives and swaps market.

Fine, in principle but what are the practical issues involved?

Question: If the fund is employing multiple managers in this capacity, should each manager engage in 'porting' their own alpha, or should one overlay manager do this for all managers?

The advantage of using just one manager is that you avoid potential duplication of trades and you simplify the administration substantially. The disadvantage is potential additional complexity in information flow, and potential delays in receiving timely asset allocation information. Both of these issues can generally be resolved through the plan's custodian.

Question: Will I end up losing return through cash balances being required to support margin needs supporting futures contracts?

No. Cash balances required to support the overlay program can remain fully invested by being 'equitised'.

Question: Should the overlay manager swap the actual market exposures of the underlying manager's positions, or should the overlay manager swap the market exposures of the underlying managers benchmarks?

That depends. If an underlying manager has a conscious country selection element to their strategy, the overlay manager should rebalance that manager's benchmark exposures. Rebalancing the actual weights owned would unwind that manager's country selection strategy. 
If, on the other hand, the underlying manager's country weights 'fall out' of a stock selection process, the overlay manager can rebalance actual country exposures, removing the country mismatches. In this case, however, the overlay manager should separately account for the rebalance trades required to rebalance the benchmark from those required to rebalance the misweights so that there is proper attribution of performance results.

Question: Are there any legal or credit issues that need to be addressed?

The Trustees will want to satisfy themselves on a number of points: For exchange traded derivatives:

- From a regulatory point of view is this an approved exchange?

- Am I contracting with a futures clearing broker with adequate capital, or with the benefit of a guarantee from an adequately capitalised parent?

- Does the clearing broker have satisfactory policies in relation to margin management?

- Is the broker posting net or gross margin?

- Does the broker have a strict policy of not advancing variation margin to clients?

For OTC contracts:

- Is the credit rating of my counterparty satisfactory?

- Can I put netting arrangements in place to reduce exposures (ISDA agreements)?

- Is there good price discovery and adequate liquidity so that I am not beholden to the counterparty with whom the position was opened?

These issues are at the end of the day largely operational matters and, provided they are dealt with in the planning stage, should not be a barrier to establishing an efficient and cost-effective programme.

\section{Leverage}

As an aside, we also want briefly to consider the almost taboo topic of leverage. So far, we have limited ourselves to strategies for improving the probability of capturing that elusive alpha that we all seek. Yet, we are forced back to the inescapable logic that alpha is a negative sum game for the market as a whole. What we have been talking about so far are strategies that will perhaps make it more likely that we shall succeed in finding alpha at the expense of some other investor.

But is there another way of improving returns for the investor and thereby reducing the risk that either contributions will need to be increased or benefits reduced? We think there is, albeit the notion is bordering on the heretical today. We are talking about the use of leverage.

Finance 1.01 tells us that, if we can borrow or lend at close to the risk-free rate, we can leverage the return of any asset up or down the market line to any level we desire. Our industry, almost uniquely, abhors the use of leverage and our regulators and tax authorities often penalise us or forbid us from using leverage.

Yet can this make sense? Every company we buy employs leverage. Indeed, we typically go round the back door and buy their leverage in the corporate bond market. Every real estate or infrastructure transaction we engage in employs leverage. Only in the area of institutional investment (hedge funds routinely employ leverage) is leverage pretty much universally precluded.

To illustrate the power of leverage, 
Table 1

\begin{tabular}{lcc}
\hline Percent & $\begin{array}{l}\text { Nomal } \\
\text { portfolio }\end{array}$ & $\begin{array}{l}\text { Geared } \\
\text { portfolio }\end{array}$ \\
\hline Equities & $60(9.0)$ & $82(9.0)$ \\
Bonds & $40(4.5$ & $40(4.5)$ \\
Borrowings & $0(4.5)$ & $(22)(4.5)$ \\
Total & $100(7.2)$ & $100(8.2)$ \\
\hline
\end{tabular}

consider this simple example. Imagine a pension plan investing 60 per cent in equities (expected returns 9 per cent), 40 per cent in bonds (expected return $41 \frac{1}{2}$ per cent), risk-free rate $4 \frac{1}{2}$ per cent. (Any similarity to any actual market is of course completely accidental!) Before costs and any realised alpha, this portfolio has an expected return of 7.2 per cent. If the required return is say, 1 per cent higher, how much leverage is required? It turns out that gearing the portfolio by 22 per cent does the trick with an end asset allocation as in Table 1.

Employing leverage alongside the considered pursuit of alpha seems to us a more balanced strategy and one which is more likely to succeed than a strategy based on alpha alone. In today's regulatory or accounting world, leveraging conventional portfolios is not generally easy. We see every likelihood of such strategies being securitised, however, so making them eligible for inclusion in many institutional portfolios.

\section{Alternatives}

In the area of alternatives, many institutional investors are moving away from single or fund-of-funds strategies towards multi-strategy solutions. Why is this happening, and what do we mean by multi-strategy solutions?

Whether a fund undertakes its own governance to build a portfolio of single strategies or hires a hedge fund-of-funds manager, both involve participation in underlying separate strategies provided by separate firms. Each participating firm charges a base and performance fee determined by their individual results. If we consider a portfolio of just two managers, one of whom performs well (manager $\mathrm{A}$ ) and the other badly (manager B), manager A collects a performance fee, manager $B$ does not. The combined result for the client may be mediocre or even poor, and yet the fund has paid performance fees not justified by the aggregate result.

This is analogous to the difference between a basket option and a portfolio of individual options.

In a multi-strategy solution, a single firm provides multiple strategies and charges a fee based on the aggregate performance. Apart from the benefit of lower costs and the certainty that performance fees are only paid when aggregate results are good, there are two additional advantages. A multi-strategy manager can change the mix of strategies he/she is employing (within permitted limits) with much greater ease than a fund-of-funds manager or a fund selecting its own single strategies. And a multi-strategy manager can bring integrated risk controls to bear at the aggregate, rather than single strategy level.

The disadvantage is that you need to be able to find a single firm with multiple credible capabilities.

\section{Case study}

At the end of 2005, Schroders announced that it had completed a major reorganisation of its own pension fund which would be implemented during Q1 2006. Schroder's fund is closed to new members (except for a small number of employees who have the option to switch into the fund) and has total assets of approaching $\$ 900 \mathrm{~m}$.

There were a number of catalysts behind rethinking the fund's strategy. 
- The experience of the bear market and its impact on the fund's funding ratio.

- The impending introduction of IFRS accounting rules and the consequent impact on the firm's financials of changes in the pension fund's funding status.

- The creation of the Pension Protection Fund (similar to the PBGC) in the UK.

- A growing realisation that existing best practice was badly flawed (as discussed at the beginning of this paper).

The process started with both the plan sponsor (in the shape of the CFO) and the Trustees defining their goals.

The plan sponsor defined goals were

(1) to minimise the long-term funding cost of the plan subject to

(2) minimising the risk at the 95 per cent confidence limit of the funding ratio of the plan dropping by more than 10 per cent in any one year. At the company level this equates to a risk budget approximately equal to 20 per cent of pre-tax profits.

The Trustee defined goals were:

(1) to maximise the funding ratio subject to

(2) minimising the risk at the 95 per cent confidence limit of the funding ratio of the plan dropping by more than 10 per cent in any one year.

To resolve these similar, but still different, objectives, the company topped up the pension plan with a cash contribution to restore the funding ratio to 100 per cent.

At this point, we were in a position to move on to a more conventional asset liability modelling process. The process incorporated the following features, however.
- The covariance matrix was built relative to liabilities.

- Expected alpha was included in return estimates.

- Alpha transport strategies were permitted.

- Both conventional and LDI fixed-income alternatives were permitted assets.

- No artificial constraints were included to drive domestic bias.

We have touched on all of these points in the paper already, with the exception of domestic bias. Almost everywhere around the world, investors have a bias in favour of their domestic market. While this might have been justified in the past on the grounds of exchange controls or lack of information, it is hard to justify in a global world. One recent cross-border transaction highlights this.

When Vodafone acquired the German company Mannesman, Mannesman's capitalisation moved from Frankfurt to London, and UK institutions, both active and passive, because of their domestic bias, were driven for benchmark risk reasons to add to their Vodafone weightings. Yet, it was quite clear that, if Mannesman had acquired Vodafone, exactly the reverse would have happened, and UK investors with their relative bias against non-UK equities would have found themselves reducing weightings. Yet, in either case, the company, its business and its cash flows would have been the same. It is hard to explain why a change in listing between London and Frankfurt should make the difference.

One other feature of this liability analysis was particular to Schroders. Our business is heavily geared to equity markets. In rising markets, our business tends to do well, and vice versa. We did not therefore want to risk double jeopardy and, for that reason, our weight 


\section{Strategies and Their Risk/Return Characteristics Excess Return vs Tracking Error}

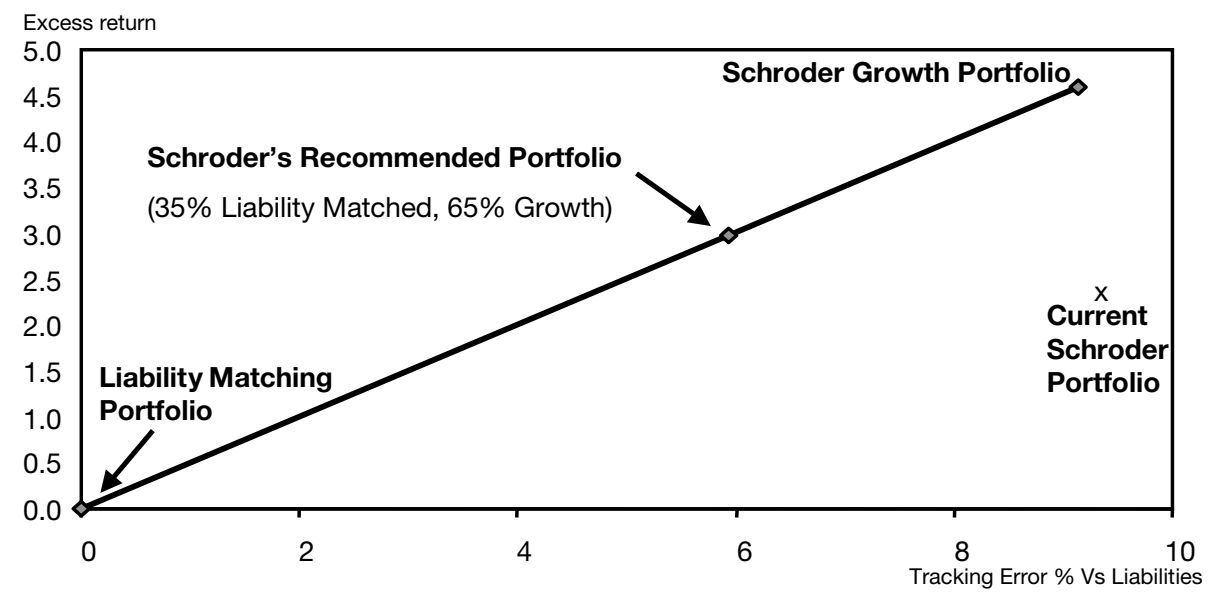

\section{Schroders}

Source: SMART, Hewitt

Figure 4 Strategies and their risk/return characteristics

to alternative assets is perhaps somewhat higher than we would have recommended for a company operating in another business.

The net effect of this study was to allow risk levels to be reduced materially while marginally improving prospective returns (see efficient frontier below). The end asset allocation was broadly 35 per cent in liability matching bonds, 36 per cent in equities with much reduced domestic bias, and 29 per cent in alternatives (see Figure 4 and Table 2).

Where was the active risk budget spent?

Given the extremely low level of real yields at the long-end in the UK, below $\frac{1}{2}$ of 1 per cent, a decision was taken to limit the liability matching part of the portfolio to 20 years. The fund therefore consciously continues to take a duration exposure against its liabilities.

Two LIBOR + strategies are employed on the cash collateral supporting the liability matching swap programme.
The rest of the active risk budget was employed within the equity and alternative allocations. Note that, although the fund has a 10 per cent exposure to large cap US equities, all this exposure arises through an alpha transport programme from Japanese equities (8 per cent) and cash ( 2 per cent). We believe that opportunities to generate alpha are significantly greater in an inefficient market such as Japan, rather than the US.

\section{Conclusion}

This paper has sought to examine a number of ways in which portfolios can be managed more efficiently to achieve overall funds' objectives, which are of course the long-term challenge of funding decent pensions at an affordable cost. There are, though, a limited number of themes running throughout.

- Benchmarks: market cap benchmarks are being challenged on many fronts. 
Table 2 Recommended strategy - growth portfolio

\begin{tabular}{|c|c|c|c|}
\hline \multicolumn{4}{|l|}{ Growth portfolio } \\
\hline Expected return* & Expected risk & $9.1 \%$ & \\
\hline & $\begin{array}{l}\text { Underlying } \\
\text { (Alpha) \% }\end{array}$ & $\begin{array}{l}\text { Allocation } \\
\text { swap \% }\end{array}$ & $\begin{array}{l}\text { Net } \\
\text { (asset) \% }\end{array}$ \\
\hline Equities & 53.0 & & 55.0 \\
\hline Specialist UK equities & 20.0 & & 20.0 \\
\hline North America equities & 0.0 & 10.0 & 10.0 \\
\hline US Smaller Cos & 1.0 & & 1.0 \\
\hline Specialist Eur ex UK equities & 11.0 & & 11.0 \\
\hline Tokyo Fund & 11.0 & -8.0 & 3.0 \\
\hline Japan Smaller Cos & 5.0 & & 5.0 \\
\hline Asian Equity Yield & 5.0 & & 5.0 \\
\hline Higher Return Bonds & 15.0 & & 15.0 \\
\hline EMD & 10.0 & & 10.0 \\
\hline Global High Yield & 5.0 & & 5.0 \\
\hline Alternative & 32.0 & & 30.0 \\
\hline SIRE & 15.0 & & 15.0 \\
\hline Diversified FOHF & 3.0 & & 3.0 \\
\hline Concentrated FOHF & 3.0 & & 3.0 \\
\hline Credit Renaissance & 2.0 & & 2.0 \\
\hline Japan Long/Short & 2.0 & & 2.0 \\
\hline Private Equity & 5.0 & & 5.0 \\
\hline Cash & 2.0 & -2.0 & 0.0 \\
\hline Total & 100.0 & 0.0 & 100.0 \\
\hline
\end{tabular}

*Return over Liabilities

— liability or absolute return alternatives (fixed income)

— benchmark unaware strategies (equities)

- Improving risk-return ratios

— '130/30' portfolios for information ratios

- benchmark unaware strategies for Sharpe ratios

- Greater efficiency and cost effectiveness

- leverage

- alpha transport

— multi-strategy.

The concepts discussed here are challenging. They are challenging for investment managers, trustees and regulators. Together, they add up to major changes in best practice. While they are undeniably demanding, we believe the potential rewards in terms of returns, and the quality and sustainability of those returns, are more than worth the effort.

(C) Schroder Investment Management Ltd

\section{Selected bibliography}

Merton, R. C. (1969) 'Lifetime Portfolio Selection under Uncertainty: The Continuous Time Case', Review of Economics and Statistics, 51, 247-57.

Merton, R. C. (1973) 'An Intertemporal Capital Asset Pricing Model', Econometrica, 41(September), in Continuous-Time Finance, Chapter 15, Basil Blackwell, Cambridge, MA.

Merton, R. C. (1975) 'Theory of Finance From the Perspective of Continuous Time', Journal of Financial and Quantitative Analysis, 10 (November).

Merton, R. C. (1990) Continuous-Time Finance, Basil Blackwell, Cambridge, MA; revised edition 1992.

\section{References}

Arnott, R. D., Hsu, J. and Moore, P. (2005)

'Fundamental Indexation', Financial Analysts Journal, 61(2), 83-99.

Clarke, R. N. M. I., de Silva, H. and Thorley, S. (2002) 'Portfolio Constraints and the Fundamental Law of Active Management', AIMR, Sept./Oct.

Fama, E. F. and French, K. R. (1992) 'The Cross-section of Expected Stock Returns', Journal of Finance, 47, 427-65.

Grinold, R. (1989) 'The Fundamental Law of Active Management', Journal of Portfolio Management, 15(3), 30-7.

Sharpe, W. F. (1964) 'Capital Asset Prices - A Theory of Market Equilibrium Under Conditions of Risk', Journal of Finance, 19, 425-42. 